\title{
Modelling and analysis of radial thermal stresses and temperature field in diesel engine valves with and without air cavity
}

\author{
Subodh Kumar Sharma ${ }^{1}$, P. K. Saini ${ }^{2}$, N. K. Samria ${ }^{3}$ \\ ${ }^{1 *}$ Department of Mechanical Engineering, National Institute of Technology Kurukshetra, Kurukshetra, INDIA \\ ${ }^{2}$ Department of Mechanical Engineering, National Institute of Technology Kurukshetra, Kurukshetra, INDIA \\ ${ }^{3}$ Department of Mechanical Engineering, Indian Institute of Management and Technology, Greater Noida, INDIA \\ Corresponding Author: e-mail: subodh_meet@yahoo.com, Tel +91-9808621738, Fax.+91-1232-228223
}

\begin{abstract}
A theoretical investigation has been undertaken to study operating temperatures, heat fluxes and radial thermal stresses in the valves of a modern diesel engine with and without air-cavity. Temperatures, heat fluxes and radial thermal stresses were measured theoretically for both cases under all four thermal loading conditions. By creating an air cavity inside the valves stem, it acts as an insulating medium and prevents the heat flow, hence the need of providing insulation coating on valves is minimized. The main motive of this is to reduce the weight of engine and cost associated with thermal coating. Results observed in the engine valves revealed that after creating an optimized air cavity in the valve, thermal stresses and temperatures at all nodal points decreases slightly. The weight of the valve decreased up to $11 \%$ without losing its strength. In addition to heat transferred by convection and radiation from combustion gases, the temperature and heat flux distributions are considerably affected by heat conduction from valve seat. The temperature field, heat transfer rate and thermal stresses were investigated with numerical simulation models using FORTRAN FE (finite element) software.
\end{abstract}

Keywords: combustion chamber, temperatures field, diesel engine valve, finite elements.

DOI: http://dx.doi.org/10.4314/ijest.v5i3.9

\section{Introduction}

In recent years, due to the rising prices of oil and the growing environmental concern, there has been an increase in demand for efficient and clean IC engines. To meet this demand, automobile industries have gradually developed engines which are more clean and efficient. In the particular case of diesel engines, remarkable progress has been made, this can be demonstrated by the fact that sales of diesel vehicles have recently overtaken gasoline car. Exhaust gas treatment technologies have also played a major role in making vehicle much cleaner. The durability and output potential of such engines is still strongly linked to the operating temperature of several fundamental components, such as cylinder bores, exhaust valves, valve bridges, valve seats and piston crowns (Sitker, 1974; Prasad and Samria, 1986;1990; Cerit, 2011). The thermal stresses developed in these fundamental components have the potential to decrease the durability and output of the engine.

In the light of above problem, research communities have drawn their attention on new trends of engine designs i.e. making it adiabatic by creating air cavities in cylinder wall, piston body and valves. The air cavity created inside the valves acts as an insulating medium and prevents the heat flow, hence the need of providing insulation coating on valves is minimised. The main motive of this is to reduce weight of engine and cost associated with thermal coating.

A model is proposed by Singh et al. (1986) to study the heat transfer in cylinder and piston assembly. By plotting the various graphs like variation of radial temperature from piston crown periphery, concludes that piston rings have higher thermal stresses and losses heat in water cooled engines. A computer simulation of the turbo-charged turbo-compounded direct-injection diesel engine system has been developed by Assanis and Heywood (1986), in their research work they describe the basic system models and their calibration and validation against available experimental engine test data. Prasad and Samria (1990) formulated the set of 
equations with the help of isotherms and based on finite difference approximation of an aluminium alloy piston and valves of a diesel engine revels that temperature increases with insulation coating and hence the thermal stresses developed also increases. Rakopoulos and Mavropoulos (1996) developed a model for the calculation of the temperature field and heat flow in the combustion chamber components of internal combustion piston engines, which occur both under steady and transient engine operating conditions. Two and three-dimensional finite-element analyses were implemented for the representation of the complex geometry metal components (piston, liner and cylinder head) and found a satisfactory degree of agreement between theoretical predictions and experimental measurements. An experimental model is prepared by Sakhrieh et al. (2010) to determine the heat release in a diesel engine have concluded that early injection timings leads to higher level of pressure and temperature in cylinder. Temperature and stress distribution were analyzed in a partial coated SI Engine's piston by Muhammet Cerit (2011) and found that the optimum coating thickness was found to be near $1 \mathrm{~mm}$ and with increases in coating thickness the surface temperature increases in a decreasing rate.

A set of heat flux data was obtained by Morel et al. (1988) in a Cummins single cylinder NH-engine coated with zirconia plasma spray. Data were acquired at two locations on the head, at several speeds and several load levels. The data showed that the peak heat flux was consistently reduced by insulation and by the increasing wall temperature. Finally they conclude that insulation and increasing wall temperatures lead to a decrease in heat transfer and thus contribute positively to thermal efficiency. After performing various experiments, Kakuda et al. (2009) concludes that thermal cycling from room temperature to $1150^{\circ} \mathrm{C}$, the thermal conductivity and diffusivity of thermal barrier coating increase. During high-temperature exposure, the microstructure of thermal barrier coatings evolves, leading to increased thermal conductivity. Raman spectra- scope apparatus used in the work. Further a numerical analysis of the heat transfer in a gas was confined by a moving piston inside a valve less cylinder was done by Catto and Prata (2000), which was presented with the help of finite volume methodology. Apart from this, Krisztina et al. (2008) presented experimental results which confirm that the heat transfer in the combustion chamber of an IC engine is mainly as a function of the level of temperature of the parts. Abu-Nanda et al., (2006) introduced thermodynamic analysis of SI Engines by implementing temperature depending specific heat and it was found that the constant specific heat models can only be used for very small temperature variations so far large changes in temperature, variable specific heat models should be implemented.

A finite element model of gasoline spark engine is successfully developed and simulated and had analyzed heat transfer during combustion process and obtains temperature distribution across the major engine component by Kandil et al. (1995) and Mon et al. (2011). Zhao (2012) investigated temperature and thermal stress field of the ceramic coated piston of diesel engine by using the wavelet finite-element method and ANSYS software. Mavropoulos (2011) presented the results from the analysis of an experimental investigation of instantaneous heat transfer phenomena occurring in both the cylinder head and exhaust manifold wall surfaces of a direct injection (DI), air-cooled diesel engine. Based on this model, the evolution of local surface heat flux during a transient event was calculated. Rakopoulos et al. (2004) presented a work on the development of a model for the calculation of the temperature field and heat flow in the combustion chamber components of internal combustion piston engines, which occur both under steady and transient engine operating conditions. Heat flux variation with crank angle was observed by Mohammadi et al. (2010) by using the quasi steady Anand model, found a good agreement with the experimental measurements.

The specific objective of this research paper is to develop an enhanced method to predict the temperature field, heat transferred and radial thermal stresses developed in diesel engine valves, considering the spatial variation of heat fluxes with and without aircavity and compare the radial thermal stresses, temperatures and heat transfer rate between the solid (without air cavity) and hollow (with air cavity) valves in four thermal loading conditions. For obtaining accurate estimations of heat flow rates, the temperature distribution in the valve should be known. Accurate heat flow and thermal deformation analysis would help in guarding against excessive stress, fatigue, corrosion, etc.

\section{Statement of the problem}

This thermal investigation is concerned with two valves (without air cavity and with air cavity) of the AV1 diesel engine, as shown in Figure 1. The engine is a single cylinder engine. The compression ratios and - consequently - the power and the torque, are different. Selected technical data for the AV1 engine is provided in Table 1. Valve shown in Figure 1 (i) is a solid valve (without air cavity) having thickness of the valve plate is $2 \mathrm{~mm}$, base diameter $30 \mathrm{~mm}$, diameter of the stem is $8 \mathrm{~mm}$ and the height of the valve is $110 \mathrm{~mm}$. Valve shown in Figure 1 (ii) is a hollow valve having air cavity has the major diameter and minor diameter of stem is $8 \mathrm{~mm}$ and $4 \mathrm{~mm}$ respectively, height is $110 \mathrm{~mm}$ and base diameter is $30 \mathrm{~mm}$. Both valves are made of alloy steel. The thermo physical materials properties and heat transfer parameter for four different case of engine loading of the valves are given in Table 2 and Table 3. In the Table 3, T and $\mathrm{H}$ represent the temperature and heat transfer coefficient and subscript $\mathrm{g}, \mathrm{s}, \mathrm{ex}, \mathrm{b}$ and $\mathrm{f}$ represent the boundaries of valve on gas side (combustion chamber), valve seat side, exhaust gas side, bush contact surface side and fresh air side. With the help of these boundary conditions temperature and thermal stresses distribution will be analyzed in the valve. 


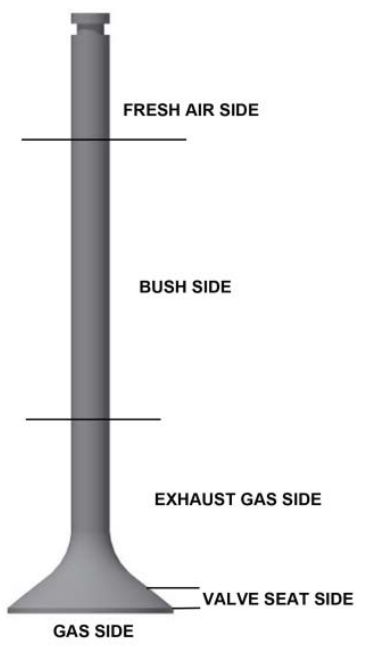

(i) DIESEL ENGINE VALVE (WITHOUT AIR CAVITY)

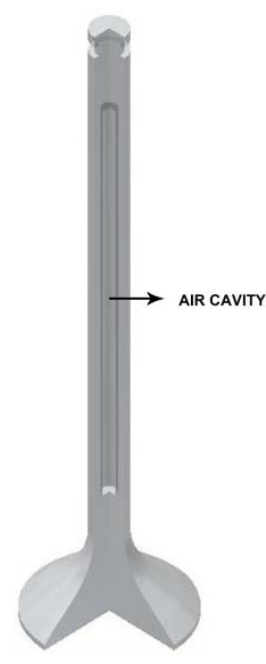

(ii) DIESEL ENGINE VALVE (WITH AIR CAVITY)

Figure 1: Diesel engine valve

Table 1: Engine and their specification

\begin{tabular}{|l|l|l|l|}
\hline Specification & Type & Specification & Type \\
\hline Cooling & Water-Cooled Engine & Governing & Class"B1" \\
\hline Model & AV1 & Power rating & 5 hp \\
\hline No. of Cylinders & 1 & Fuel injection & Direct Injection \\
\hline Cubic Capacity (ltr) & 0.553 & Rated Speed (rpm) & 1500 \\
\hline $\begin{array}{l}\text { Overall Dimensions of the } \\
\text { standard engine }\end{array}$ & $\begin{array}{l}617 \text { X 504 X 843 } \\
\text { (L X B X H) }\end{array}$ & & \\
\hline
\end{tabular}

\section{Analytical procedure for temperature and radial thermal stress}

The following procedure is followed to analyze the temperature and radial thermal stress in the valve through finite element method.

Step 1: Initially provide the value of nodes, elements, constants, different convective boundaries and variables needed in the program.

Step2: Initialize the input data.

Step3: Use scale factor to change the model node value to actual node value.

Step4: Make the conductive, convective and contact matrix and then developed D and DI matrix (D inverse matrix) with the help of input data (value of nodes, elements, constants, different convective boundaries and variables)

Step5: Compute temperature at every nodal point with the use of DI matrix.

Step6: Calculate the heat supplied by the gases to the valve $\left(\mathrm{H}_{\mathrm{g}}\right)$, heat reject to air $\left(\mathrm{H}_{\mathrm{a}}\right)$, heat reject to water $\left(\mathrm{H}_{\mathrm{w}}\right)$.

Step7: Search the nodal points which have the same temperature value, then plot constant temperature (isotherms) line in the model.

Step8: Find the radial thermal stress at all the nodal point with the use of temperature measured at that nodal point (step 5).

Step9: Search the nodal points which have the same radial thermal stress values, then plot radial thermal stress field in the model. 


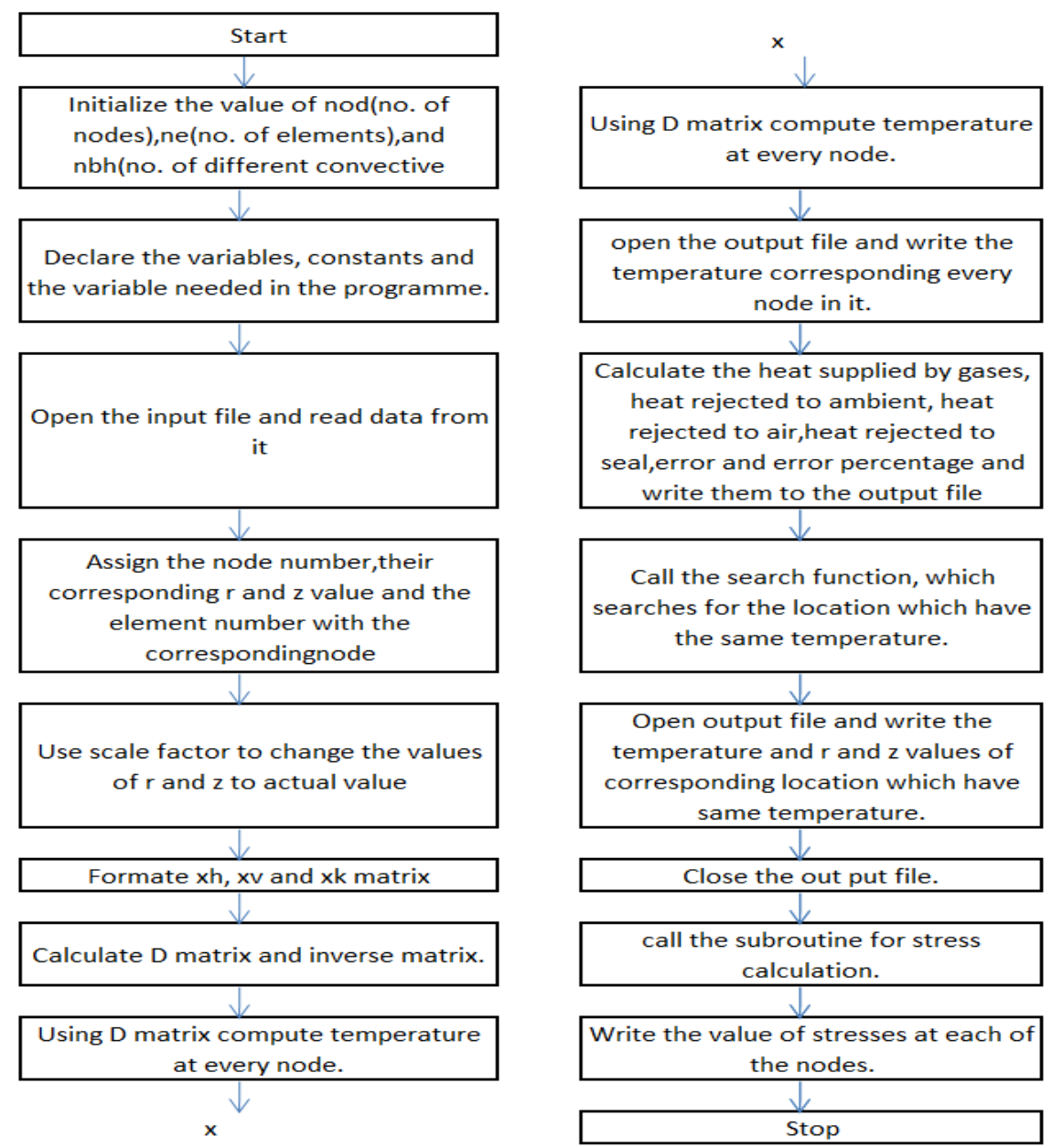

Figure 2: Flow Chart

\section{Finite element formulation of heat Transfer equations}

In the theory of finite element analysis, first the proper variational principle is selected and then the function involved is expressed in terms of approximate assumed displacements, which satisfy the given boundary conditions. Then by minimizing the approximate function a set of governing equations is developed. In this heat transfer equations are formulated by using finite element method for conduction, convection and for contact boundaries.

\subsection{Heat transfer equation for conduction}

The three dimensional generalized governing differential equation for heat conduction can be represented by Prasad and Samria (1990):

$\frac{\partial}{\partial \mathrm{x}}\left[\mathrm{K}_{\mathrm{X}}\left(\frac{\partial \mathrm{T}}{\partial \mathrm{X}}\right)\right]+\frac{\partial}{\partial \mathrm{Y}}\left[\mathrm{K}_{\mathrm{Y}}\left(\frac{\partial \mathrm{T}}{\partial \mathrm{Y}}\right)\right]+\frac{\partial}{\partial \mathrm{Z}}\left[\mathrm{K}_{\mathrm{Z}}\left(\frac{\partial \mathrm{T}}{\partial \mathrm{Z}}\right)\right]+\mathrm{q}_{\mathrm{E}}=\rho \mathrm{C} \frac{\partial \mathrm{T}}{\partial \tau}$

Where,

$\mathrm{K}_{\mathrm{X}}, \mathrm{K}_{\mathrm{Y}}, \mathrm{K}_{\mathrm{Z}}$ - Thermal conductivity in $\mathrm{X}, \mathrm{Y}$ and $\mathrm{Z}$ direction respectively

$\mathrm{q}_{\mathrm{E}}-$ Heat conduction per unit volume

$\rho$ - Density of the material

C - Heat capacity of the material

For isotropic material the thermal conductivity on all the three direction are constant, i.e. $K_{X}, K_{Y}, K_{Z}=K$

And in cylindrical co-ordinates three dimensional generalized governing differential equation for heat conduction can be represented as $[1,4]$; 
$\nabla^{2} \mathrm{~T}=\frac{\partial^{2} \mathrm{~T}}{\partial \mathrm{r}^{2}}+\frac{1}{\mathrm{r}}\left(\frac{\partial \mathrm{T}}{\partial \mathrm{r}}\right)+\frac{1}{\mathrm{r}}\left(\frac{\partial^{2} \mathrm{~T}}{\partial \theta^{2}}\right)+\frac{\partial^{2} \mathrm{~T}}{\partial \mathrm{Z}^{2}}$

Let us consider that there are " $N$ " numbers of nodal points having temperature $t_{1}, t_{2}, t_{3} \ldots . . t_{n}$ whose values are to be determined by finite element method. Mon (2011) suggested that finite element formulation depends on both the governing equation as well as on the imposed boundary condition. Here the principle of minimization is used in order to get the unknown temperatures. First the variation integrals are differentiated with respect to the corresponding nodal points and equated to zero to yield the temperature at that point. Let us consider a triangular element having nodes i, j, k in anticlockwise direction. Assuming a linear polynomial equation of temperature can be represented as:

$$
\mathrm{t}^{\mathrm{e}}=\mathrm{c}_{1}+\mathrm{c}_{2} \mathrm{r}+\mathrm{c}_{3} \mathrm{z}
$$

Let $t_{1}, t_{2}, t_{3}$ and $\left(r_{i}, z_{i}\right),\left(r_{j}, z_{j}\right),\left(r_{k}, z_{k}\right)$ be the temperature and (r, z) co-ordinates of an element having nodes $i$, j, $k$ respectively. The variational integral in axis symmetric co-ordinate system for heat conduction can be represented as;

$\chi_{\mathrm{K}}^{(\mathrm{e})}=\frac{1}{2}(2 \pi \mathrm{K}) \iint_{\mathrm{A}}\left[\left[\frac{\partial \mathrm{t}}{\partial \mathrm{r}}\right]^{2}+\left[\frac{\partial \mathrm{t}}{\partial \mathrm{z}}\right]^{2}\right] \mathrm{rdrdz}$

Here a linear polynomial is chosen to approximate the variation of temperature within an element in terms of the temperatures at the nodal points of the elements. Polynomials are chosen in such a way that continuity is maintained along the element boundaries. The shape function $\mathrm{N}_{\mathrm{i}}, \mathrm{N}_{\mathrm{j}}$ and $\mathrm{N}_{\mathrm{k}}$ are chosen for a particular element according to variations of the parameters within the elements. The Polynomial chosen in terms of shape function is given by:

$t(r, z)=\left[\begin{array}{lll}N_{i} & N_{j} & N_{k}\end{array}\right]\left\{\begin{array}{c}t_{i} \\ t_{j} \\ t_{k}\end{array}\right\}=[N]^{(e)}\{t\}^{(e)}$

Where the constants are

$N_{i}=\frac{\left[a_{i}+b_{i} r+c_{i} z\right]}{\Delta}$

$N_{j}=\frac{\left[a_{j}+b_{j} r+c_{j} z\right]}{\Delta}$

$N_{k}=\frac{\left[a_{k}+b_{k} r+c_{k} z\right]}{\Delta}$

$a_{i}=\left(r_{j} z_{k}-z_{j} r_{k}\right), \quad a_{j}=\left(r_{k} z_{i}-z_{k} r_{i}\right)$,

$b_{i}=\left(z_{j}-z_{k}\right), \quad b_{j}=\left(z_{k}-z_{i}\right)$,

$a_{k}=\left(r_{i} z_{j}-z_{j} r_{i}\right)$,

$c_{i}=\left(r_{k}-r_{j}\right)$,

$c_{j}=\left(r_{i}-r_{k}\right)$,

$b_{k}=\left(z_{j}-z_{i}\right)$,

$c_{k}=\left(r_{j}-r_{i}\right)$

Differentiating the above equation (4) with respect to co-ordinates $r$ and $z$;

$\frac{\partial \mathrm{t}^{(\mathrm{e})}}{\partial \mathrm{r}}=\left[\begin{array}{lll}\mathrm{b}_{\mathrm{i}} & \mathrm{b}_{\mathrm{j}} & \mathrm{b}_{\mathrm{k}}\end{array}\right]\{\mathrm{t}\}^{(\mathrm{e})}=[\mathrm{b}]^{(\mathrm{e})}\{\mathrm{t}\}^{(\mathrm{e})}$

$\frac{\partial \mathrm{t}^{(\mathrm{e})}}{\partial \mathrm{z}}=\left[\begin{array}{lll}\mathrm{c}_{\mathrm{i}} & \mathrm{c}_{\mathrm{j}} & \mathrm{c}_{\mathrm{k}}\end{array}\right]\{\mathrm{t}\}^{(\mathrm{e})}=[\mathrm{c}]^{(\mathrm{e})}\{\mathrm{t}\}^{(\mathrm{e})}$

With the help of equation (5) and equation (6), put the value $\frac{\partial \mathrm{t}^{(\mathrm{e})}}{\partial \mathrm{r}}$ and $\frac{\partial \mathrm{t}^{(\mathrm{e})}}{\partial \mathrm{z}}$ in equation (3) and then minimized the conductive variational integral of heat transfer $\left(\chi_{\mathrm{K}}^{(\mathrm{e})}\right)$ with respect to the nodal points that yields a set of linear equation as a contribution to the global set of equation.

$\frac{\partial x_{k}^{(e)}}{\partial\{t\}^{(e)}}=\left(2 \pi \mathrm{KA}^{(e)} r_{c}\right)\left[[b]^{(e)^{t}}[b]^{(e)}\right]+\left[[c]^{(e)^{t}}[c]^{(e)}\right]\{t\}^{(e)}$

Where $\quad \iint_{A} r d r d z=A^{(e)} r_{c}, \quad r_{c}=\frac{r_{i}+r_{j}+r_{k}}{3}$

Let $\mathrm{A}^{(\mathrm{e})} \mathrm{r}_{\mathrm{c}}=\mathrm{V}^{(\mathrm{e})}$; where $\mathrm{V}^{(\mathrm{e})}$ is the volume of an element.

After putting the value of $[\mathrm{b}]^{(\mathrm{e})},[\mathrm{b}]^{(\mathrm{e}) \mathrm{t}},[\mathrm{c}]^{(\mathrm{e})}$ and $[\mathrm{c}]^{(\mathrm{e}) \mathrm{t}}$ in equation $(7)$, generate the stiffness matrix. 
$\frac{\partial \chi_{k}^{(e)}}{\partial\{t\}^{(e)}}=\left(2 \pi K V^{(e)}\right)\left[\left[\begin{array}{ccc}b_{i}^{2}+c_{i}^{2} & b_{i} b_{j}+c_{i} c_{j} & b_{i} b_{k}+c_{i} c_{k} \\ b_{j} b_{i}+c_{j} c_{i} & b_{j}^{2}+c_{j}^{2} & b_{j} b_{k}+c_{j} c_{k} \\ b_{k} b_{i}+c_{k} c_{i} & b_{k} b_{j}+c_{k} c_{j} & b_{k}^{2}+c_{k}^{2}\end{array}\right]\right]\{t\}^{(e)}$

$\frac{\partial x_{k}^{(e)}}{\partial\left\{t^{(e)}\right.}=\left[\left[\begin{array}{lll}\mathrm{k}_{11} & \mathrm{k}_{12} & \mathrm{k}_{13} \\ \mathrm{k}_{21} & \mathrm{k}_{22} & \mathrm{k}_{23} \\ \mathrm{k}_{31} & \mathrm{k}_{32} & \mathrm{k}_{33}\end{array}\right]\right]\left\{\begin{array}{l}\mathrm{t}_{\mathrm{i}} \\ \mathrm{t}_{\mathrm{j}} \\ \mathrm{t}_{\mathrm{k}}\end{array}\right\}=[\mathrm{k}]^{(\mathrm{e})}\{\mathrm{t}\}^{(\mathrm{e})}$

Where $[\mathrm{k}]^{(\mathrm{e})}=$ stiffness matrix

\subsection{Heat transfer equation for contact boundary}

The generalized governing differential equation of heat transfer for contact boundary can be represented by Prasad and Samria (1990) and Sitker (1974). When two elements (e) and (p) are having a contact boundary, whose contact is imperfect but if there is a contact co-efficient for heat transfer, in that case heat transfer can be represented as:

$\mathrm{q}_{\mathrm{c}}=\mathrm{K}_{1}\left[\frac{\partial \mathrm{T}}{\partial \mathrm{n}}\right]^{\mathrm{e}}=-\mathrm{K}_{2}\left[\frac{\partial \mathrm{T}}{\partial \mathrm{n}}\right]^{\mathrm{p}}$

Where, $\mathrm{q}_{\mathrm{c}}=\mathrm{h}_{\mathrm{c}}\left(\mathrm{T}^{\mathrm{e}}-\mathrm{T}^{\mathrm{p}}\right)$

Variational formulation for contact boundary between 2 elements (e) and (p) can be written as.

$\chi_{\text {bcont. }}=\frac{\mathrm{h}_{\mathrm{c}}}{2} \int_{\mathrm{si}}^{\mathrm{sj}}\left[\{\mathrm{t}\}^{\mathrm{e}}-\{\mathrm{t}\}^{\mathrm{p}}\right]^{2} 2 \pi \mathrm{rds}$

On solving it further in similar fashion as done in convective boundary, it has been found that contact boundary variational integral of heat transfer after differentiation with respect to temperature of contact surface that yields a set of linear equations as a contribution to the global set of equation.

$\frac{\left(\partial \chi_{\text {bcont. }}\right) e}{\partial\left\{\mathrm{t}_{\mathrm{s}}\right\}^{\mathrm{e}}}=\frac{2 \pi \mathrm{h}_{\mathrm{c}} \mathrm{r}_{\mathrm{m}} \mathrm{r}_{\mathrm{ij}}}{6 \cos \theta}\left[\begin{array}{cc}2-\frac{\varepsilon}{2} & 1 \\ 1 & 2+\frac{\varepsilon}{2}\end{array}\right]\left\{\begin{array}{l}\left\{\left\{\mathrm{t}_{\mathrm{s}}\right\}^{\mathrm{e}}-\left\{\mathrm{t}_{\mathrm{s}}\right\}^{\mathrm{p}}\right\}_{1} \\ \left.\left\{\mathrm{t}_{\mathrm{s}}\right\}^{\mathrm{e}}-\left\{\mathrm{t}_{\mathrm{s}}\right\}^{\mathrm{p}}\right\}_{2}\end{array}\right\}$

\subsection{Heat transfer equation for convective boundary}

The generalized governing differential equation for heat convection can be represented by Prasad and Samria (1990):

$-\mathrm{K}\left(\frac{\partial \mathrm{T}}{\partial \mathrm{n}}\right)=\mathrm{h}\left(\mathrm{T}-\mathrm{T}_{\infty}\right)$

The variational integral formulation for convective boundary can be represented as;

$\delta \chi_{\text {bconv. }}=\int_{\mathrm{A}}-\mathrm{K}\left(\frac{\partial \mathrm{T}}{\partial \mathrm{n}}\right) \delta \mathrm{Td} S=\int_{\mathrm{A}} \mathrm{h}\left(\mathrm{T}-\mathrm{T}_{\infty}\right) \delta \mathrm{TdS}$

$\delta \chi_{\text {bconv. }}=\int_{\mathrm{i}}^{\mathrm{j}}-\mathrm{Kr}\left(\frac{\partial \mathrm{T}}{\partial \mathrm{n}}\right) \delta \mathrm{Td} S$

Where, $i$ and $\mathrm{j}$ are the two nodal points of the element of side $\mathrm{s}$.

Let $\frac{\mathrm{r}}{\mathrm{s}}=\cos \theta,\left(\frac{\partial \mathrm{T}}{\partial \mathrm{n}}\right)=\mathrm{h}\left(\mathrm{t}-\mathrm{t}_{\infty}\right)$ and $\mathrm{ds}=\frac{\mathrm{dr}}{\cos \theta}$

$\mathrm{T}(\mathrm{s})=\mathrm{N}_{\mathrm{si}} \mathrm{t}_{\mathrm{i}}+\mathrm{N}_{\mathrm{sj}} \mathrm{t}_{\mathrm{j}}=\left[\mathrm{N}_{\mathrm{s}}\right]\{\mathrm{t}\}$

Where $\mathrm{N}_{\mathrm{si}}$ and $\mathrm{N}_{\mathrm{sj}}$ are the shape factor of convective boundaries. Which are shown in equations (18) and (19).

$N_{s i}=\frac{s_{j}-s}{s_{i j}}=\frac{\frac{\left(r_{j}-r\right)}{\frac{\cos \theta}{r_{i j}}}}{\frac{\cos \theta}{\cos \theta}}=\frac{\left(r_{j}-r\right)}{r_{i j}} ; N_{s j}=\frac{s-s_{i}}{s_{i j}}=\frac{\frac{\left(r-r_{j}\right)}{\cos \theta}}{\frac{r_{i j}}{\cos \theta}}=\frac{\left(r-r_{i}\right)}{r_{i j}}$

With the help of these equations (16), (17) and (18), variational integral of heat transfer for convective boundary after differentiation with respect to temperature can be represent as 
$\frac{\partial \chi_{\text {bconv. }}}{\partial\left\{\mathrm{t}_{\mathrm{s}}\right\}}=\frac{2 \pi \mathrm{hr}_{\mathrm{m}} \mathrm{r}_{\mathrm{ij}}}{6 \cos \theta}\left[\begin{array}{cc}2-\frac{\varepsilon}{2} & 1 \\ 1 & 2+\frac{\varepsilon}{2}\end{array}\right]\left\{\begin{array}{l}\mathrm{t}_{\mathrm{si}} \\ \mathrm{t}_{\mathrm{sj}}\end{array}\right\}-\left\{\begin{array}{l}\left(\mathrm{ht}_{\infty}\right)_{1} \\ \left(\mathrm{ht}_{\infty}\right)_{2}\end{array}\right\}$

Where, $r_{m}=\frac{r_{i}+r_{j}}{2}, r_{i j}=r_{j}-r_{i}, r_{j}=r_{m}-\frac{r_{i j}}{2}, \varepsilon=\frac{r_{i j}}{r_{m}}$

$\frac{\partial \text { X }_{\text {bconv. }}}{\partial\left\{\mathrm{t}_{\mathrm{s}}\right\}}=[\mathrm{H}]_{\mathrm{s}}\{\mathrm{t}\}_{\mathrm{s}}-\left\{\mathrm{ht}_{\infty}\right\}$

\section{Temperature and stress field calculation}

The prediction of the temperature distribution in the valves, involves the solution of the heat conduction equation, heat transfer to the contact surface and heat convection equation with the appropriate boundary conditions. For this purpose 3-dimensional axis symmetric finite-element model case was considered for steady state engine operation. These models give satisfactory results with significant computer time economy. (3-dimensional axis symmetric model is same as 2-dimensional model, because for particular one nodal value angular variation is zero about the symmetric axis. So coordinates value $\mathrm{r}, \mathrm{z}$ can be represented by $\mathrm{x}, \mathrm{y}$ respectively).

Variational integral of heat transfer globally (for all the elements) is founded by adding heat conduction equation (9), heat transfer to contact boundary equation (13) and heat convection equations (20). And this can be represented as in equation (21).

$\frac{\partial\{X\}^{g}}{\partial\{t\}^{g}}=[K]^{g}\{t\}^{g}+[H]^{g}\{t\}^{g}-\left\{h t_{\infty}\right\}^{g}=0$

Where, $\partial\{X\}^{g}=$ Variational integral of heat transfer globally.

Let; $\quad[K]^{(g)}+[H]^{g}=[D]^{g}$

$$
\begin{aligned}
& \left\{h t_{\infty}\right\}^{(g)}=\{V\}^{(g)} \\
& \{t\}^{(g)}=[D I]^{(g)}\{V\}^{(g)}
\end{aligned}
$$

From the equation (5.4), temperatures at all the nodes of the valve are to be finding out, which is to be represented in Figures 3 to 6.

$$
\begin{aligned}
\text { where }[D I]^{(g)} & =[D]^{(g)^{-1}}, \\
\{t\}^{(g)} & =\text { global temperature }
\end{aligned}
$$

After prediction the temperature at all the nodes of the valve, radial thermal stress will be analyzed with the help of following equations (25), (26) and (27) to show the radial strain, angular strain and axial strain respectively;

$$
\begin{aligned}
\varepsilon_{r} & =\frac{\sigma_{r}}{E}-\frac{v}{E} \sigma_{\theta}-\frac{v}{E} \sigma_{Z}+\alpha_{t}\left(T-T_{0}\right) \\
\varepsilon_{\theta} & =-v \frac{\sigma_{r}}{E}+\frac{1}{E} \sigma_{\theta}-\frac{v}{E} \sigma_{Z}+\alpha_{t}\left(T-T_{0}\right) \\
\varepsilon_{Z} & =-v \frac{\sigma_{r}}{E}-\frac{v}{E} \sigma_{\theta}+\frac{1}{E} \sigma_{Z}+\alpha_{t}\left(T-T_{0}\right)
\end{aligned}
$$

Thus stress strain relationship can be represented in matrix form as shown in equation (28)

$$
\begin{aligned}
& {\left[\begin{array}{ccc}
1 & -v & -v \\
-v & 1 & -v \\
-v & -v & 1
\end{array}\right]\left\{\begin{array}{l}
\sigma_{r} \\
\sigma_{\theta} \\
\sigma_{z}
\end{array}\right\}=E\left[\left\{\begin{array}{l}
\varepsilon_{r} \\
\varepsilon_{\theta} \\
\varepsilon_{z}
\end{array}\right\}-\alpha_{t}\left(T-T_{0}\right)\left\{\begin{array}{l}
1 \\
1 \\
1
\end{array}\right]\right.} \\
& {[P]\{\sigma\}=E\left[\{\varepsilon\}-\left\{\varepsilon_{0}\right\}\right]}
\end{aligned}
$$

Where $[\mathrm{P}]$ is the Position matrix, $\sigma_{r}=$ Radial stress, $\sigma_{\theta}=$ Angular stress, $\sigma_{z}=$ Axial stress. After inversion of position matrix, put the value of this in the above equation and find the stresses at all the nodes of the valve.

$$
\begin{aligned}
& \{\sigma\}=[P]^{-1} E\left[\{\varepsilon\}-\left\{\varepsilon_{0}\right\}\right] \\
& {[P]^{-1}=\frac{(1+v)(1-v)}{(1+v)^{2}(1-2 v)}\left[\begin{array}{ccc}
1 & v_{1} & v_{1} \\
v_{1} & 1 & v_{1} \\
v_{1} & v_{1} & 1
\end{array}\right]} \\
& \sigma=\frac{E(1-v)}{(1-2 v)(1+v)}\left[\begin{array}{ccc}
1 & v_{1} & v_{1} \\
v_{1} & 1 & v_{1} \\
v_{1} & v_{1} & 1
\end{array}\right]\left[\{\varepsilon\}-\left\{\varepsilon_{0}\right\}\right]
\end{aligned}
$$


Where, $\sigma=$ thermal stress, thermal strain $\left\{\varepsilon_{0}\right\}=\alpha_{\mathrm{t}}\left(\mathrm{T}-\mathrm{T}_{0}\right)$; and simple strain $\{\varepsilon\}$ $=\left\{\begin{array}{l}\varepsilon_{\mathrm{r}} \\ \varepsilon_{\theta} \\ \varepsilon_{\mathrm{z}}\end{array}\right\} ; \mathrm{v}$ is the poission ratio and it is 0.33 and $\mathrm{v}_{1}=\frac{\mathrm{v}}{1-\mathrm{v}}$

From the equation (32), Radial thermal stresses at all the nodes of the valve have been calculated and are represented in Figures 7 to 10 .

The solution of the reduced steady-state heat conduction problem in the $\mathrm{r}, \mathrm{z}$ coordinate system is found by sub-dividing the valves into 117 elements and 89 nodes. Every element exists in thermal equilibrium with its adjacent elements. Computational code is generated to solve mathematical model through FORTRAN language and temperature and radial thermal stresses at all the nodal points are analyzed, then temperature field (isothermal distribution curve) and radial thermal stresses distribution in the diesel engine valve model is obtained.

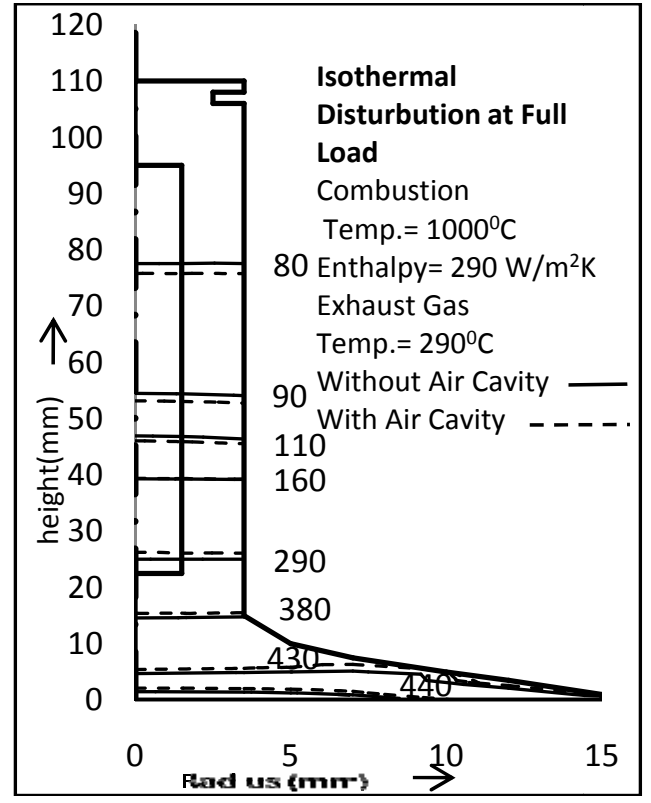

Figure 3: Isothermal Distributions (Full-load cond.)

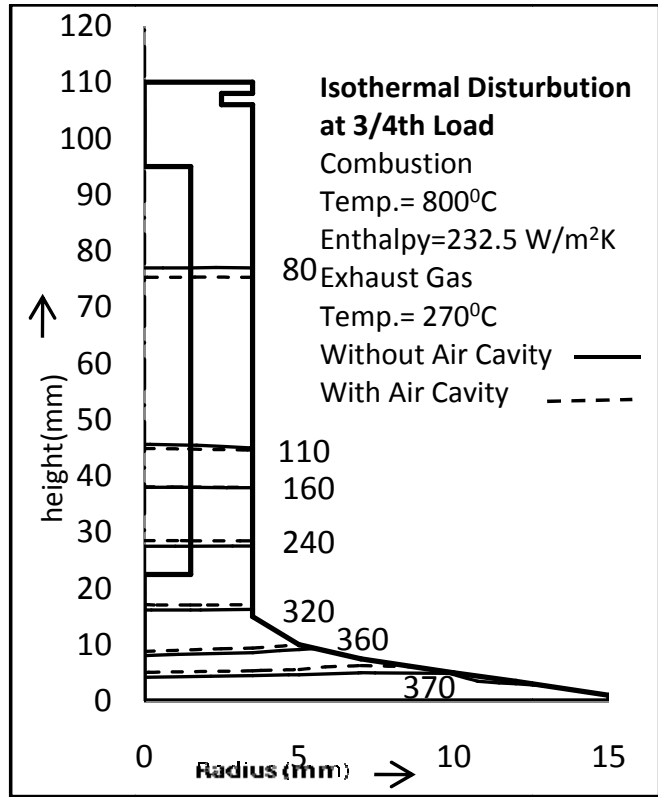

Figure 4: Isothermal Distributions (3/4 load cond.)

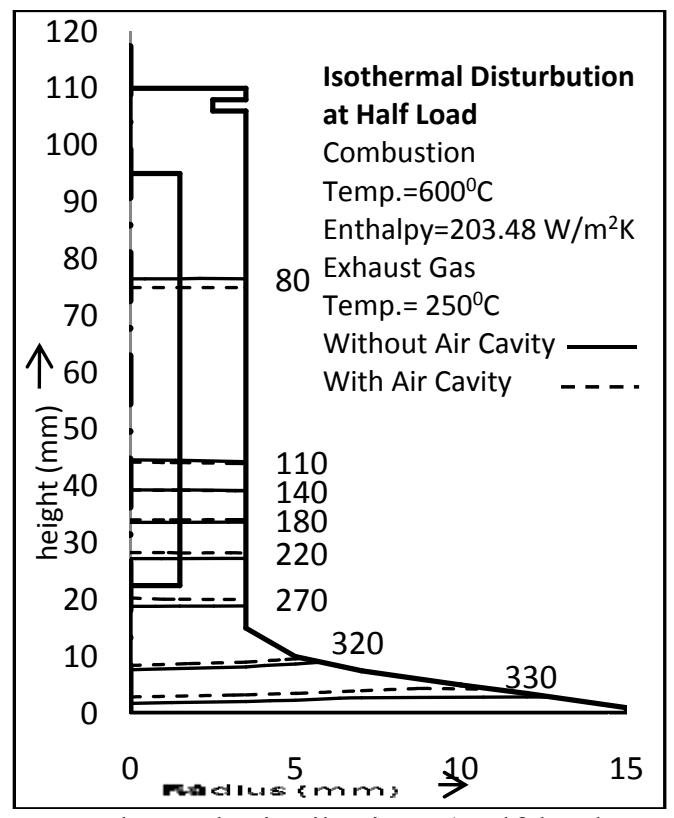

Figure 5: Isothermal Distributions (Half-load cond.)

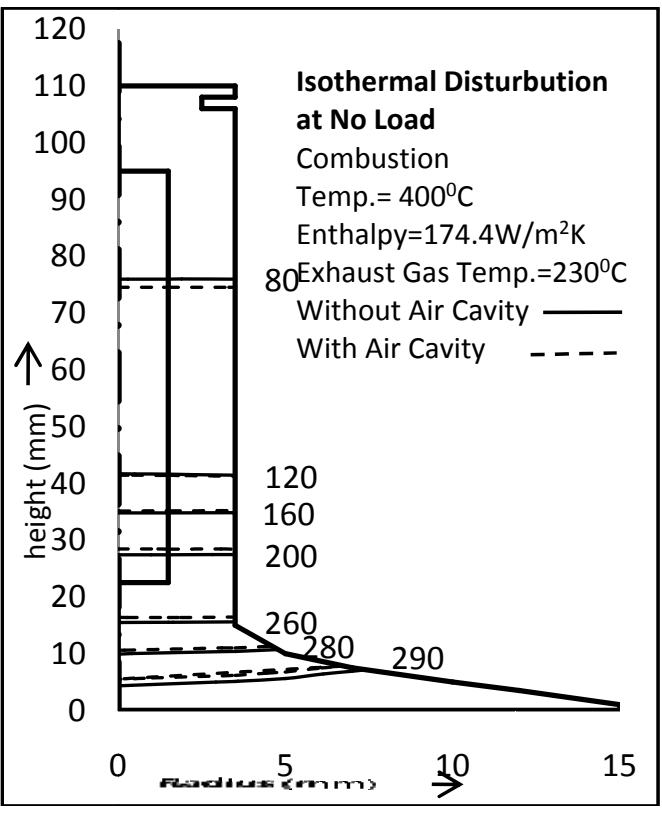

Figure 6: Isothermal Distributions (No-load cond.) 


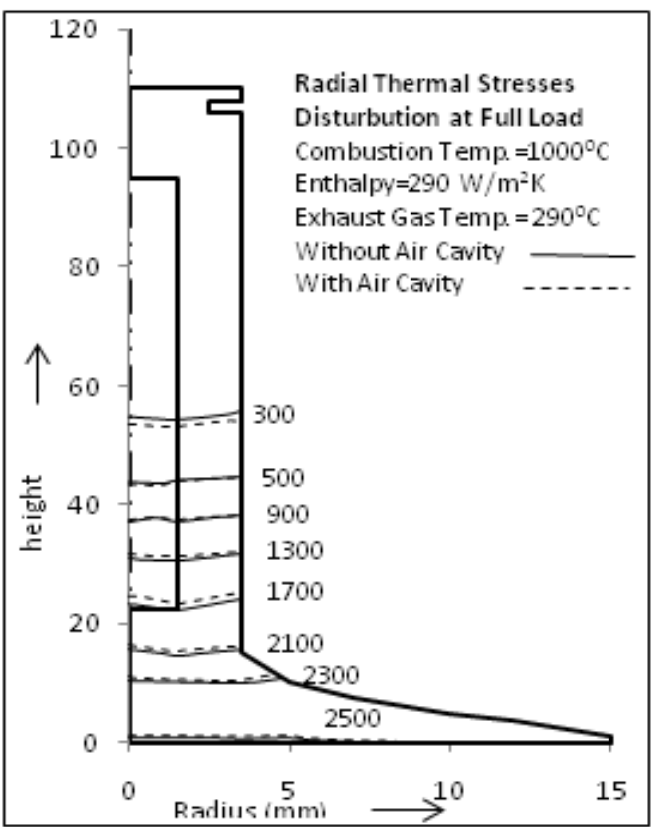

Figure 7: Full-load conditions

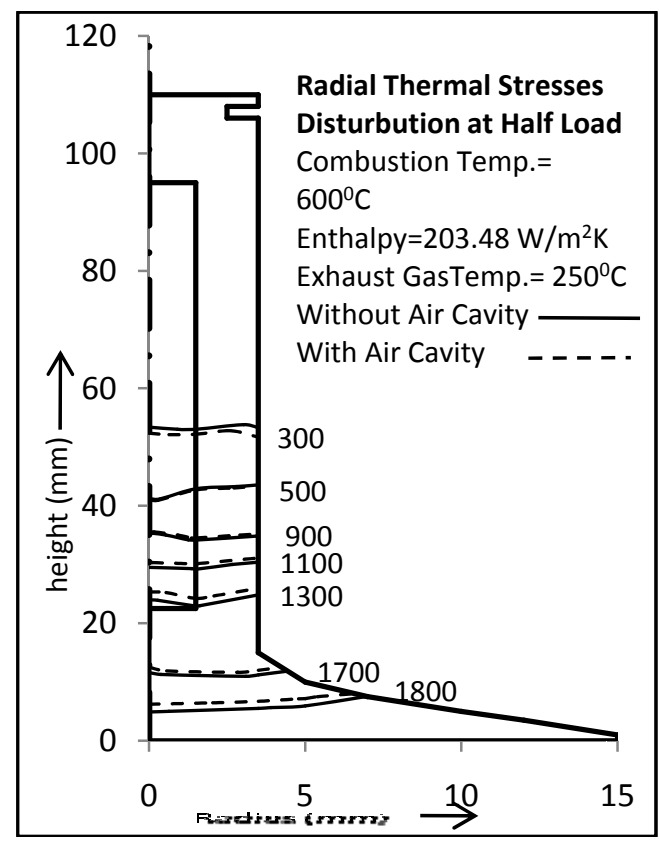

Figure 9: Half-load condition

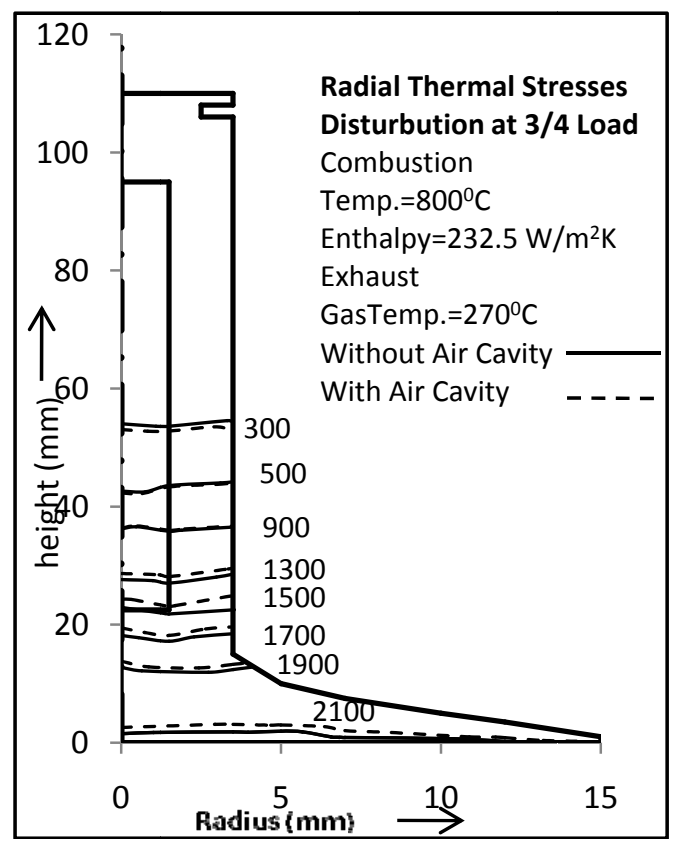

Figure 8: Third forth- load condition

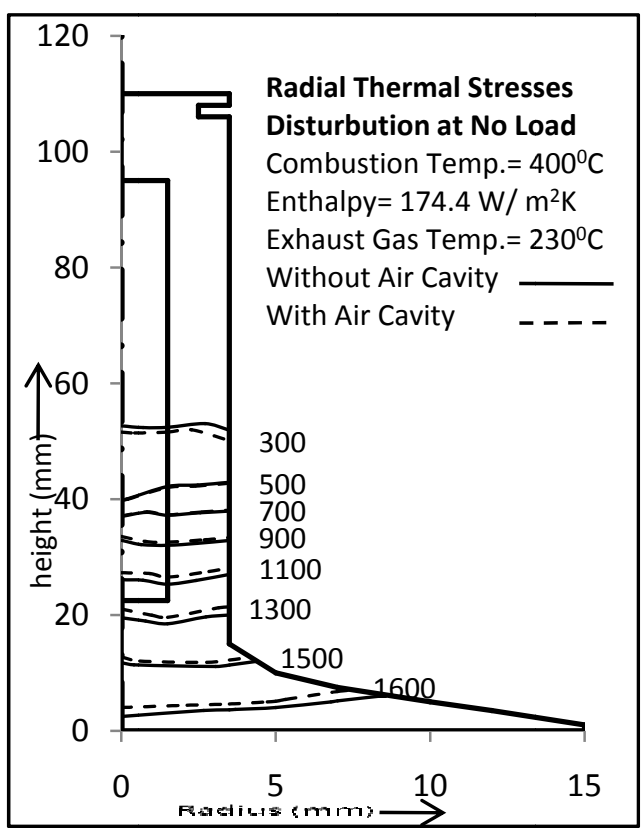

Figure 10: No-load condition

Table 2: Thermo physical properties of metal

\begin{tabular}{|l|l|l|l|l|l|}
\hline Sr.No. & Properties & Units & Aluminium & Cast iron & Steel \\
\hline 1 & Thermal conductivity & $\mathrm{W} / \mathrm{m} \mathrm{K}$ & 175 & 70 & 50 \\
\hline 2 & Density & $\mathrm{Kg} / \mathrm{m}^{3}$ & 2700 & 7200 & 7850 \\
\hline 3 & Thermal diffusivity & $\mathrm{m}^{2} / \mathrm{hr}$ & 0.259 & 0.04563 & 0.044 \\
\hline 4 & Specific Heat & $\mathrm{Kcal} / \mathrm{kg}^{0} \mathrm{C}$ & 0.214 & 0.14 & 0.113 \\
\hline
\end{tabular}




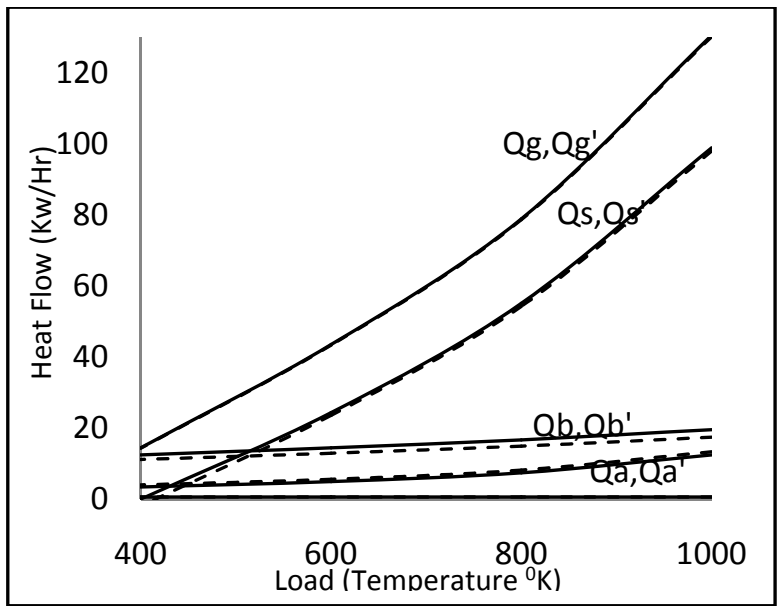

Figure 11: Heat flow pattern for four different load cases

Table 3: Heat transfer parameter for four different cases of engine loading

\begin{tabular}{|l|l|l|l|l|}
\hline Parameter & Full Load & 3/4 Load & Half Load & No Load \\
\hline Temperature in ${ }^{0} \mathrm{C}$ & 1000 & 800 & 600 & 400 \\
\hline $\mathrm{T}_{\mathrm{g}}($ Gas side $)$ & 300 & 120 & 120 & 120 \\
\hline $\mathrm{T}_{\mathrm{s}}$ (Valve Seat side) & 25 & 25 & 25 & 25 \\
\hline $\mathrm{T}_{\mathrm{a}}$ (Air side) & 80 & 80 & 80 & 80 \\
\hline $\mathrm{T}_{\mathrm{b}}$ (Bush Side) & 290 & 270 & 250 & 230 \\
\hline $\mathrm{T}_{\mathrm{ex}}($ Exhaust Gas side $)$ & \multicolumn{5}{|l|}{} \\
\hline Heat transfer coefficients $\left(\mathrm{W} / \mathrm{m}^{2} \mathrm{~K}\right)$ & 290 & 232.5 & 203.48 & 174.4 \\
\hline $\mathrm{H}_{\mathrm{g}}($ Gas side $)$ & 1859.2 & 1859.2 & 1859.2 & 1859.2 \\
\hline $\mathrm{H}_{\mathrm{w}}($ water side $)$ & 23 & 23 & 23 & 23 \\
\hline $\mathrm{H}_{\mathrm{a}}$ (Air side $)$ & 1745 & 1745 & 1745 & 1745 \\
\hline $\mathrm{H}_{\mathrm{b}}$ (Bush side) & 175 & 175 & 175 & 175 \\
\hline $\mathrm{H}_{\mathrm{ex}}$ (Exhaust Gas side) & 175 \\
\hline
\end{tabular}

Table 4: Maximum and minimum range of temperature and radial thermal stress in the valve

\begin{tabular}{|l|c|c|c|c|}
\hline Engine loading condition & $\begin{array}{c}\text { Max. } \\
\text { Temperature } \\
\left({ }^{\circ} \mathrm{C}\right)\end{array}$ & $\begin{array}{c}\text { Min. } \\
\text { Temperature } \\
\left({ }^{\circ} \mathrm{C}\right)\end{array}$ & $\begin{array}{c}\text { Max. Stress } \\
(\mathrm{MPa})\end{array}$ & $\begin{array}{c}\text { Min. Stress } \\
(\mathrm{MPa})\end{array}$ \\
\hline Case 1 (No Load) & 290 & 80 & 1600 & 300 \\
\hline Case 2 (Half Load) & 330 & 80 & 1800 & 300 \\
\hline Case 3 (3/4 Load) & 370 & 80 & 2100 & 300 \\
\hline Case 4 (Full Load) & 440 & 80 & 2500 & 300 \\
\hline
\end{tabular}

Table 5: Maximum and minimum value of heat flow rate $(\mathrm{kW} / \mathrm{hr})$ in the valve

\begin{tabular}{|l|c|c|c|c|}
\hline \multirow{2}{*}{ Particulars } & \multicolumn{2}{|c|}{ with air (Q) } & \multicolumn{2}{c|}{ without air (Q') } \\
\cline { 2 - 5 } & Maximum & Minimum & Maximum & Minimum \\
\hline Qg (Gas Side) & 130.2878 & 14.28624 & 130.60616 & 14.41556 \\
\hline Qs (Seat Side) & 98.97205 & 0 & 98.04006 & 0 \\
\hline Qb (Bush side) & 17.42614 & 11.10911 & 19.54745 & 12.43298 \\
\hline Qa (Air Side) & 13.30671 & 3.98244 & 12.43071 & 3.414 \\
\hline
\end{tabular}




\section{Discussion of Results}

As result shows that due to air cavity thermal energy is much more utilize to generate work output. It reduces the weight and cost of the valves because no thermal barrier coating or insulating coating is required on the bottom surface of the valves. This new method should be supported by a research methodology comprising the application of thermodynamic principles and the fundamental equations of heat transfer. The justification for undertaking this research on heat transfer in engines is based on the potential benefits of this kind of investigation. Here finite element analysis is used to obtained temperature and corresponding thermal stress. The thermal gradient and thermal stress developed are accurate as they are satisfying heat flow boundary conditions. Hence, the results are meaningful. The results of calculations carried out for radial thermal stresses and isothermal distribution in diesel engine valve at four different loading condition and have been presented in Figures 3 to 6 and Figures 7 to 10 , respectively.

The radial thermal stresses and isothermal distribution were measured in the valves for four different engine loading conditions (Full load, $3 / 4$ load, half load and no load) having resulting gas temperatures of $1000^{\circ} \mathrm{C}, 800^{\circ} \mathrm{C}, 600^{\circ} \mathrm{C}$ and $400^{\circ} \mathrm{C}$ respectively and exhaust gas temperature of $290^{\circ} \mathrm{C}, 270^{\circ} \mathrm{C}, 250^{\circ} \mathrm{C}$ and $230^{\circ} \mathrm{C}$ respectively. In the Figures 3 to 6 and Figures 7 to 10 , solid lines show the radial thermal stresses and temperature field distribution of valve without air cavity while dotted lines represented the valve with air cavity. The temperature field increases in all the cases from minimum $70^{\circ} \mathrm{C}$ onwards to maximum on the plate. It can be observed that the maximum radial stress and temperature appears near the valve seat. The maximum and minimum range of temperature and radial thermal stress in the valve for four loading conditions are shown in Table 4. Table 5 shows the minimum and maximum value of heat transfer rate through valve. Figure 11 shows the variation of heat gain ( $\mathrm{Qg}$ and $\left.\mathrm{Qg}^{\prime}\right)$ by the valve from the hot gases, heat lost to valve seat (Qs and $\left.\mathrm{Qs}^{\prime}\right)$, heat lost to incoming air (Qa and $\mathrm{Qa}^{\prime}$ ) and heat lost to valve bush $\left(\mathrm{Qb}^{\mathrm{and}} \mathrm{Qb}\right.$ ') at the four different thermal loading conditions with and without air cavity. It seems that heat received from the hot gas is increased with increase in the engine combustion temperature (Tg). Similarly heat lost to seat, heat lost to bush and heat lost to air increases with engine combustion temperature. For both the cases heat gain by the valve from the hot gases is same but heat lost to valve seat, air and valve bush is slightly decreases. As result indicates that due to presence of air gap inside the valve stem, there is no such appreciable decrease towards the heat flow but the mass of the valve is reduced without affecting much of its strength. So with the help of this air cavity inside the valve, weight and cost associated with the engine is reduced.

\section{Nomenclature}

$\mathrm{K}_{\mathrm{X}}, \mathrm{K}_{\mathrm{Y}}, \mathrm{K}_{\mathrm{Z}}$ - Thermal conductivity in $\mathrm{X}, \mathrm{Y}$ and $\mathrm{Z}$ direction respectively $\left(\mathrm{Wm}^{-1} \mathrm{~K}^{-1}\right)$

$\mathrm{q}_{\mathrm{E}}$ - Heat conduction per unit volume $\left(\mathrm{J} \mathrm{m}^{-3}\right)$

$\rho$ - Density of the material $\left(\mathrm{kg} \mathrm{m}^{-3}\right)$

$\mathrm{A}^{(\mathrm{e})}=$ Area of the Element $(\mathrm{e})\left(\mathrm{m}^{2}\right)$

$\mathrm{C}=$ Specific Heat

(e) $=$ Element Number (e)

$\mathrm{E}=$ Young's Modulus of Elasticity $\left(\mathrm{N} \mathrm{m}^{-2}\right)$

$\{\mathrm{F}\}^{(\mathrm{e})}=$ Force on the Element (e)

$\{\mathrm{F}\}_{\mathrm{P}}=$ Force Due To Distributed Load

$\{\mathrm{F}\}_{\in_{0}}=$ Force Due To Initial Strain

$\{\mathrm{F}\}_{\sigma_{0}}=$ Force Due To Initial Stress

$\mathrm{i}, \mathrm{j}, \mathrm{k}=$ Nodal Point Number of an element

$\mathrm{q}_{\mathrm{g}}=$ Heat Generation per Unit Volume $\left(\mathrm{J} \mathrm{m}^{-3}\right)$

$r_{i j}=r_{j}-r_{i}$, Difference Between $r$ Co-ordinates Of Nodal Point i \& j

$s_{i j}=$ Distance between Nodal Points $\mathrm{i} \& \mathrm{j}$

$\mathrm{T}=$ Temperature Variable $\left({ }^{\circ} \mathrm{C}\right)$

$\mathrm{T}_{\alpha}=$ Surrounding Temperature $\left({ }^{\circ} \mathrm{C}\right)$

$\mathrm{T}_{\mathrm{s}}=$ Surface Temperature $\left({ }^{\circ} \mathrm{C}\right)$

$\alpha=$ Thermal Expansion

$\delta_{\mathrm{i}}, \delta_{\mathrm{j}}, \delta_{\mathrm{k}}=$ Displacement of Nodal Points i, j, k

$\{\delta\}^{(\mathrm{e})}=$ Displacement of Element

$\chi=$ Variational Integral

$\chi_{b}=$ Boundary Term of Variational Integral

$[\mathrm{k}]^{(\mathrm{e})}=$ stiffness matrix

$\mathrm{h}_{\mathrm{c}}=$ Convective heat transfer co-efficient $\left(\mathrm{Wm}^{-2} \mathrm{k}^{-1}\right)$

$\varepsilon=$ linear strain 
$\sigma=$ stress

\section{References}

Abu-Nada, E., Al-Hinti, I., Al-Sarkhi, A., and Akash, B., 2006. Thermodynamic modeling of spark-ignition engine: Effect of temperature dependent specific heats, International Communications in Heat and Mass Transfer, Vol. 33, pp. 1264-1272.

Assanis, D. N. and Heywood, J. B., 1986. Development and use of a computer simulation of the turbocompounded diesel engine performance and component heat transfer studies, SAE Technical Paper 860329.

Bin Zhao, 2012. Thermal stress analysis of ceramic coated diesel engine piston based on the wavelet finite element method, journal of engineering mechanics, Vol. 138, No. 1, pp. 143-149.

Buttsworth, D. R., Agrira, A., Malpress, R. and Yusaf, T., 2011. Simulation of instantaneous heat transfer in spark ignition internal combustion engines: Unsteady thermal boundary layer modeling, Journal of Engineering for Gas Turbines Power, Vol. 133, pp. 22802/1-22802/5.

Catto, A.G., and Prata, A.T., 2000. A numerical study of instantaneous heat transfer during compression and expansion in pistoncylinder geometry, International Journal of Numerical Heat Transfer, Part A, Vol. 38, pp. 281-303.

Heywood, J.B., 1988. Internal Combustion Engine Fundamentals, 4th ed. published, Mc. Graw-Hill Inc New York, NY.

Kakuda, T.R., Limarga, A.M., Bennett, T.D. and Clarke, D.R., 2009. Evolution of thermal properties of EB-PVD 7YSZ thermal barrier coating with thermal cycling, Acta Materialia, Vol. 57, pp. 2583-2591.

Kandil, A., El-Kady, A.A., and El-Kafrawy, A., 1995. Transient thermal stress analysis of thick-walled cylinders, International Journal of Mechanical Science, Vol. 37, pp.721-732.

Mavropoulos, G.C., 2011. Experimental Study of the Interactions Between Long and Short-Term Unsteady Heat Transfer Responses on the In-Cylinder and Exhaust Manifold Diesel Engine Surfaces, Applied Energy, Vol.88, No.3, pp. 867-881.

Mohammadi, A., Yaghoubi, M., 2010. Estimation of instantaneous heat transfer coefficient in spark-ignition engines, International Journal of Thermal Science, Vol. 49, pp. 1309-1317.

Morel, T., Wahiduzzaman, S., Fort, E.F., 1988. Heat transfer experiments in an insulated diesel, SAE Paper 880186.

Muhammet Cerit, 2011. Thermo mechanical analysis of a partially ceramic coated piston used in an SI engine, Surface \& Coatings Technology, Vol. 205, pp. 3499-3505.

Prasad, R. and Samria N.K., 1991. Transient Heat Transfer Studies on a diesel engine valve, International Journal of Mechanical Science, Vol. 33, pp. 179-195.

Prasad, R. and Samria, N.K., 1990. Heat transfer and stress fields in the inlet and exhaust valve of a semi-adiabatic diesel engine, Computers \& structures, Vol. 34, No. 5, pp. 165-711.

Prasad, R. and Samria, N.K., 1990. Transient heat transfer analysis an internal combustion engine piston, Computers \& Structures, Vol. 34, No. 5, pp. 781-193.

Rakopoulos, C.D. and Mavropoulos, G.C., 1996. Study of the Steady and Transient Temperature Field and Heat Flow in the Combustion Chamber Components of a Medium Speed Diesel Engine Using Finite Element Analyses, International Journal of Energy Research, Vol. 20, No.5, pp. 437-464.

Rakopoulos, C.D., Antonopoulos, K.A., Rakopoulos, D.C. and Giakoumis, E.G., 2004. Investigation of the temperature oscillations in the cylinder walls of a diesel engine with special reference to the limited cooled case, International Journal of Energy Research, Vol. 28, pp. 977-1002.

Sakhrieh, A., Abu-Nada, E. and Akash, B., 2010. Computational thermodynamic analysis of compression ignition engine, International Communication in Heat and Mass Transfer, Vol. 37, pp. 299-303.

Singh, V.P., Upadhyay, P.C. and Samria, N.K., 1986. Some heat transfer studies on a diesel engine piston, International Journal of Heat Mass Transfer, Vol. 29, No. 5, pp. 812-814.

Sitker, G., 1974. Heat transfer and thermal loading in internal combustion engine, 2nd ed. published, Academia Kiado Budapest.

Soltani, R., Samadi, H., Garcia, E. and Coyle, T.W., 2005. Development of alternative thermal barrier coatings for diesel engines, SAE International 01, pp. 65-72.

Thet T.Mon, Rizalman Mamat, and Kamsah, N., 2011. Thermal analysis of SI Engine using simplified finite element model, Paper Presented at the World Congress Engineering 2011,Vol. III, July 6-8.

Uzuneanu, K., Panait, T. and Dragan, M., 2008. Modeling the heat transfer in the piston head of a spark ignition engine supplied with ethanol-gasoline blend, COFRET'08, June 11-13.

\section{Biographical notes}

Subodh Kumar Sharma received M. Tech. from Utter Pradesh Techanical University Lucknow, India in 2008. He is a part time Research Scholar in the Department of Mechanical Engineering, National Institute of Technology Kurukhsetra, India and working as an associate professor in the Department of Mechanical Engineering, Krishna Institute of Engineering and Technology Ghaziabad, India. His research interests include finite element analysis, thermal analysis and mechanical analysis of internal combustion diesel engine. He has He has published three in referred national and international journals He is a Fellow of IE (India). 
Dr. P. K. Saini received M.Tech. and Ph.D. from the Department of Mechanical Engineering, National Institute of Technology Kurukhsetra, India. He is working as an Associate Professor in the Department of Mechanical Engineering, National Institute of Technology Kurukhsetra, India. He has more than 6 years of experience in teaching and research. His current area of research includes mechanical system design and triabology. He has published more than tweleve papers in referred national and international journals. He has also presented more than ten research articles in national and international conferences. He has written few books related to his research work. He is currently dealing with few projects sponsored by government of India.

Dr. N. K. Samria is a Professor in the Department of Mechanical Engineering, IIMT Greater Noida, India. He has more than 36 years of experience in teaching and research. He worked as a professor in Banaras Hindu University, Banaras, India. His current area of research includes finite element analysis of diesel engine. He has published more than forty papers in referred national and international journals. He has also presented more than thirty research articles in national and international conferences. He has written few books related to his research work. He is currently dealing with few projects sponsored by government of India.

Received January 2013

Accepted March 2013

Final acceptance in revised form May 2013 